\title{
Locating and repurposing anesthetic machines as intensive care unit ventilators during the COVID-19 pandemic
}

\author{
Beverley A. Orser, MD, PhD, FRCPC, FCAHS, FRSC $\cdot$ Robert Byrick, MD, \\ FRCPC · Richard Cooper, MD, FRCPC · Elihu Henry, RRT • \\ Philip Lau, CCAA, RRT, FCSRT, BSc $\cdot$ Brian Rittenberg, DDS, \\ MSc, FRCD $(C) \cdot$ Julian Wiegelmann, MD, FRCPC
}

Received: 3 April 2020/Revised: 3 April 2020/Accepted: 4 April 2020/Published online: 14 April 2020

(C) Canadian Anesthesiologists' Society 2020

\section{To the Editor,}

There is a widely reported shortage of ventilators to treat critically ill patients during the coronavirus disease (COVID-19) pandemic. ${ }^{1}$ Governments have acted quickly to engage industry partners in the manufacturing of new equipment, including ventilators; however, this process will take time. Given that the number of patients in severe respiratory failure may soon exceed the number of ventilators currently available in Canadian hospitals, interim measures are needed to prevent rationing decisions until new ventilators are available.

We formed a multidisciplinary working group with the mission of creating a centralized registry of ventilators in out-of-hospital premises, as an interim measure to maximize existing resources that could be rapidly deployed. We also examined issues related to the repurposing of anesthesia workstations (hereafter referred to as anesthetic machines) as intensive care unit (ICU) ventilators. We write to share the team's experience and

B. A. Orser, MD, PhD, FRCPC, FCAHS, FRSC ( $₫)$.

J. Wiegelmann, MD, FRCPC

Department of Anesthesiology and Pain Medicine, University of

Toronto, Toronto, ON, Canada

e-mail: beverley.orser@utoronto.ca

Sunnybrook Health Sciences Centre, Toronto, ON, Canada

R. Byrick, MD, FRCPC · R. Cooper, MD, FRCPC

Department of Anesthesiology and Pain Medicine, University of

Toronto, Toronto, ON, Canada

E. Henry, RRT · P. Lau, CCAA, RRT, FCSRT, BSc

Sunnybrook Health Sciences Centre, Toronto, ON, Canada

B. Rittenberg, DDS, MSc, FRCD(C)

Sinai Health System, Toronto, ON, Canada strategy and to encourage other Canadian anesthesiologists and intensivists to consider adopting a similar approach.

One important lesson that the working group learned early on was that in the context of a rapidly developing public health crisis, like the one we are facing today, uncoordinated and non-convergent efforts lead to multiple requests to provide various types of information from already burdened sources. In Ontario, this duplication of effort has been minimized through effective communication among the provincial ministry of health, professional regulatory agencies, and professional medical and dental societies. Recently, the provincial veterinary society also became engaged.

We aimed to identify all available certified and serviced anesthetic machines and ventilators located in out-ofhospital surgical facilities in Ontario that could provide controlled or assisted ventilation and that might be available for emergency purposes.

We approached the two major manufacturers of anesthetic machines in Canada, GE Healthcare and Draeger Medical Canada, who agreed to provide a list of all serviced anesthesia machines within Ontario. We also identified medical directors of out-of-hospital premises, and cross-referenced this list with the databases generously made available by GE Healthcare and Draeger Canada. Through this strategy, we identified at least 91 candidate anesthetic machines. These data have now been made available to the Ontario Ministry of Health and Long-Term Care. It should be emphasized that industry partners should be informed about any redistribution of these machines as the situation evolves, to ensure the provision of the consumable items as required.

Anesthetic machines are not intended for long-term use as ICU ventilators, and their use for this purpose is considered "off-label." As such, our working group asked 
Health Canada to establish a policy regarding the repurposing of anesthetic machines as ICU ventilators during the COVID-19 pandemic. On 25 March 2020, Health Canada released a document entitled Notice: Importation or sale of ventilators - use of US FDA guidance and Canadian requirements for authorization under the Interim Order, ${ }^{2}$ which refers to U.S. Food and Drug Administration guidelines. ${ }^{3}$ These documents are valuable references for both hospitals and physicians.

It is also important to recognize that the use of anesthetic machines as ICU ventilators necessitates certain safety precautions. As a result, new guidelines have been produced by the American Society of Anesthesiologists and the Anesthesia Patient Safety Foundation (Guidance on Purposing Anesthesia Machines as ICU Ventilators). ${ }^{4}$ Our group has now modified these guidelines for the Canadian setting (Canadian Guidance on Purposing Anesthetic Machines as ICU Ventilators). In addition, strategies to protect anesthetic machines from contamination have also been published by the Anesthesia Patient Safety Foundation. ${ }^{5}$

We hope this information will be helpful to our colleagues in other provinces who are seeking options for the provision of emergency ICU ventilator care with anesthetic machines during the COVID-19 pandemic.

\section{References}

1. Ranney $M L$, Griffeth V, Jha AK. Critical supply shortages - the need for ventilators and personal protective equipment during the
Covid-19 pandemic. N Engl J Med 2020. DOI: https://doi.org/10. 1056/NEJMp2006141.

2. Government of Canada. Notice: Importation or sale of ventilators use of US FDA guidance and Canadian requirements for authorization under the Interim Order - March 25, 2020. Available from URL: https://www.canada.ca/en/health-canada/ services/drugs-health-products/medical-devices/activities/announc ements/covid19-notice-importation-sale-ventilators.html (accessed April 2020).

3. U.S. Food and Drug Administration. Guidance Document: Enforcement Policy for Ventilators and Accessories and Other Respiratory Devices During the Coronavirus Disease 2019 (COVID-19) Public Health Emergency. Guidance for Industry and Food and Drug Administration Staff - March 2020. Available from URL: https://www.fda.gov/regulatory-information/searchfda-guidance-documents/enforcement-policy-ventilators-and-acce ssories-and-other-respiratory-devices-during-coronavirus (accessed April 2020).

4. American Society of Anesthesiologists; Anesthesia Patient Safety Foundation. A Guidance on Purposing Anesthesia Machines as ICU Ventilators - 2020. Available from URL: https://www.asahq. org/in-the-spotlight/coronavirus-covid-19-information/purposinganesthesia-machines-for-ventilators (accessed April 2020).

5. Anesthesia Patient Safety Foundation. FAQ on Anesthesia Machine Use, Protection, and Decontamination During the COVID-19 Pandemic. Last updated April 1, 2020. Available from URL: https://www.apsf.org/faq-on-anesthesia-machine-useprotection-and-decontamination-during-the-covid-19-pandemic/ \#machine (accessed April 2020).

Publisher's Note Springer Nature remains neutral with regard to jurisdictional claims in published maps and institutional affiliations. 